\title{
Investigation on the Mechanical Properties of TIG Welded AA6061 Alloy Weldments Using Different Aluminium Fillers
}

\author{
L.H. Shah, Nur Azhani Abdul Razak, A. Juliawati, and M. Ishak
}

\begin{abstract}
In this research, the effect of filler weld material on the mechanical properties of tungsten inert gas (TIG) welded AA6061 alloy weldments have been investigated. The microstructure of the base metal (BM) as well as weld metal (WM) and heat affected zone (HAZ) was analyzed using optical microscopy and scanning electron microscopy (SEM), and the Vickers hardness of the samples were compared. Corrosion resistance of the weld area was investigated in natural seawater solution. Results for both filler samples indicate that the strength of the WMs and HAZs is lower compared to BMs. In addition to that, the weld joints of ER4043 samples show relatively higher hardness compared to ER4047 samples. The corrosion test results show that ER4043 sample has a lower corrosion rate value compared to ER4047. It can be concluded that ER4043 samples show better Vickers hardness value and corrosion resistance compared to ER4047 samples.
\end{abstract}

Index Terms - TIG welding, AA6061, corrosion, Vickers hardness

\section{INTRODUCTION}

$\mathrm{A}$ l-Mg-Si alloys such as AA6061 exhibit moderately high strength and excellent corrosion resistance, and have numerous applications, including welded fabrications. Due to this, AA6061 finds broad use in welded structural members such as truck and marine frames, railroad cars, and pipelines [1],[2]. The good corrosion resistance of AA6061 is due to the formation of a thin, hard and compact film of adherent aluminium oxide on the surface. However, aluminium oxide may dissolve in some chemical solutions, such as strong acids and alkalis leading to a rapid corrosion of aluminium and its alloy. Furthermore, the corrosion resistance could be reduced by the presence of the weldment in the base metal [3].

To alleviate hot cracking in weldments of AA6061, Si-rich filler metals such as the common ER4043 is generally used [1]-[4]. This type of cracking is found to occur depending on filler composition and dilution [5]. Moreover, Prasad and Ramanaiah et al. found that longitudinal cracking occurred

Manuscript received July 18, 2013.

Author is a lecturer in the Faculty of Mechanical Engineering, Universiti Malaysia Pahang, 26600 Pekan, Pahang, Malaysia (e-mail: luqmanhakim@ump.edu.my). The author would like to acknowledge Universiti Malaysia Pahang for the research funds. when AA6061 was welded with Mg-rich filler metal ER5356 but not with Si-rich filler metal ER4043 [6]. Si-rich filler metals have also shown to prevent the build-up of brittle intermetallic compound (IMC) layer, and minimizing its thickness [7]. Numerous researches have been conducted on ER5356 and ER4043 filler metals, since both are the most common filler metals to be used when welding AA6061 sheets. In addition, Song et al. have reported that filler metals such as ER4047 (Si content 13 wt.\%) which possess quite similar compositions could rival the output quality of ER4043 [7]. However, information on the effects of alternative filler metals such as ER4047 on the AA6061 weldment is scarce.

The objective of this research is to conduct a comparative study on filler metal effects on AA6061 alloy weld joint. The commercially known ER4043 filler wire and another similarly non-heat treatable high Si content ER4047 filler wire were used. The effect of ER4043 and ER4047 Si-rich filler metals on the hardness and the corrosion rate of the weld joint was compared and analyzed.

\section{EXPERIMENTAL METHOD}

\section{A. Welding Process}

The base metals were welded together with ER4043 or ER4047 filler metals using the Miller Dynasty 200 tungsten inert gas (TIG) arc welding device available in the Faculty of Manufacturing Engineering in Universiti Malaysia Pahang. All samples will be named 4043 filler samples or 4047 filler samples from now on. Details of the welding parameters are presented in Table I.

TABLE I

FIXED AND VARIED TIG WELDING PARAMETERS

\begin{tabular}{ll} 
Welding parameter & Value \\
& \\
Background current $\left(\mathrm{I}_{\mathrm{b}}\right)$ & $20 \%$ of peak current \\
Pulse on time & $40 \%$ of cycle time \\
Filler diameter & $1.6 \mathrm{~mm}$ \\
Shielding gas & Argon \\
Frequency & $1.8 \sim 2 \mathrm{~Hz}$ \\
Peak current $\left(\mathrm{I}_{\mathrm{p}}\right)$ & $40 \sim 60 \mathrm{~A}$ \\
\hline
\end{tabular}




\section{B. Materials}

Material used in this study is AA6061 alloy in the form of $50 \times 25 \times 2 \mathrm{~mm}$ plates in as-prepared condition, with ER4043 and ER4047 as filler metals. Chemical compositions of the materials used are given in Table II.

TABLE II

CHEMICAL COMPOSITION (wt.\%) of AA6061 BASE METAL AS WELL AS ER4043 [8] AND ER4047 FILLER METALS [9].

\begin{tabular}{lcccccccc} 
Materials & $\mathrm{Mg}$ & $\mathrm{Si}$ & $\mathrm{Fe}$ & $\mathrm{Cr}$ & $\mathrm{Zn}$ & $\mathrm{Cu}$ & $\mathrm{Mn}$ & $\mathrm{Al}$ \\
\hline AA6061 & 0.88 & 0.68 & 0.4 & 0.17 & - & 0.2 & .08 & Bal. \\
& & & & & & & & \\
ER4043 & 0.05 & 5 & 0.3 & - & - & 0.12 & .05 & Bal. \\
& & & & & & & & \\
ER4047 & 0.01 & 11.9 & 0.14 & - & $<$ & $<$ & .01 & Bal. \\
& & & & & 0.01 & 0.01 & & \\
\hline \hline
\end{tabular}

\section{Sample preparation}

The specimens were manually grinded in the alternating longitudinal and latitudinal direction with 240, 320, 400 and 600 grit papers in that order, polished using 6 and $0.05 \mu \mathrm{m}$ polishing plates to remove major scratches and finally etched by immersing in an $\mathrm{HF}$ aqueous solution at ambient temperature. Microstructural characteristics and Vickers hardness testing were investigated using Zeiss EVO50 scanning electron microscopy (SEM) device and Matsuzawa MMT-X7 hardness tester, respectively.

\section{Electrochemical testing}

Corrosion experiments were performed in natural seawater obtained from Pantai Lagenda, Kuala Pahang, Pahang, Malaysia at ambient temperature. Potentiodynamic polarization tests were carried out using IVMAN Potentio/Galvanostat equipment. The schematic picture of the set up is shown in Fig.1. The working electrode, consisting only of the weld fusion zone of specimens, were sheared and prepared using epoxy resin and plastic tubing so that only these regions were exposed to the test solution [10]. The resin only exposes approximately $0.14 \mathrm{~cm}^{2}$ of the specimen in the

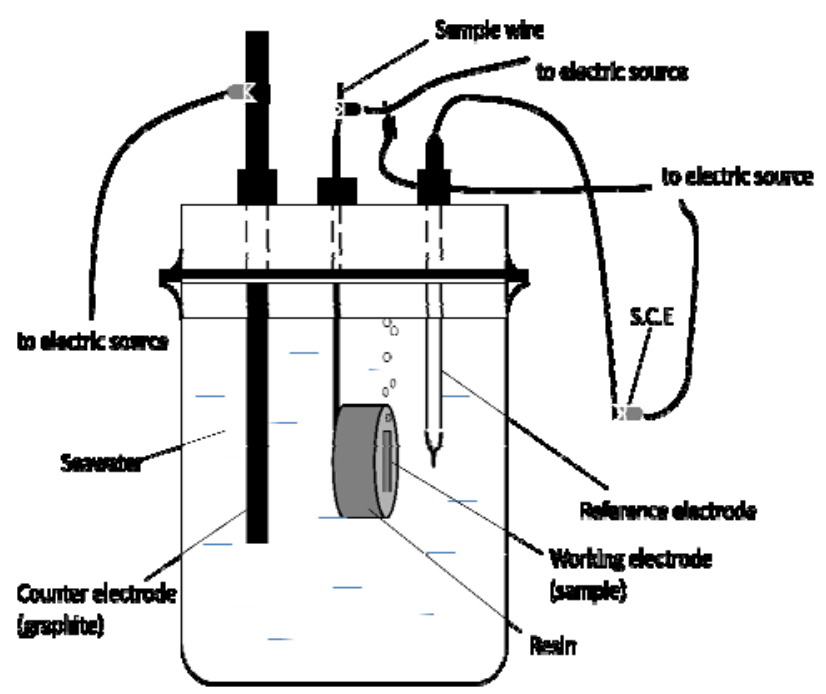

Fig.1 Schematic picture of the electrochemical testing seawater solution. A saturated calomel electrode (SCE) was used as the reference electrode, where as graphite was used as the counter electrode [8]. The details of the parameters of the potentiodynamic polarization are shown in Table III. The corrosion rates of both sets of samples were plotted and measured.

TABLE III POTENTIODYNAMIC POLARIZATION TEST PARAMETERS

\begin{tabular}{ll} 
Test parameters & Value \\
\hline Initial E & $-1 \mathrm{~V}$ \\
Final E & $1 \mathrm{~V}$ \\
Scan rate & $4 \mathrm{mVs}^{-1}$ \\
Sampling time & $1 \mathrm{~s}$ \\
Sample area & $0.14 \mathrm{~cm}^{2}$ \\
Density & $2.7 \mathrm{gcm}^{-3}$ \\
\hline \hline
\end{tabular}

\section{RESULTS}

\section{A. Weld quality and microstructural analysis}

Fig.2 below shows the weld joints of both filler materials. Both fillers show very good beads with minimal welding
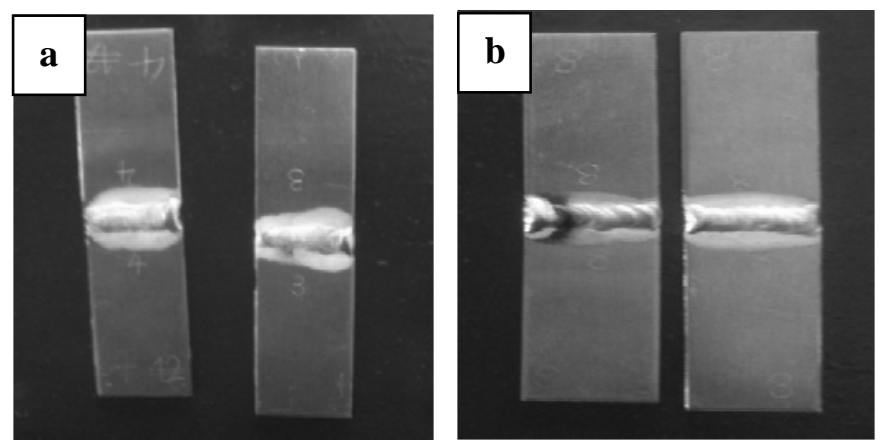

Fig.2 The weld joints using a) 4043 filler material and b) 4047 filler material

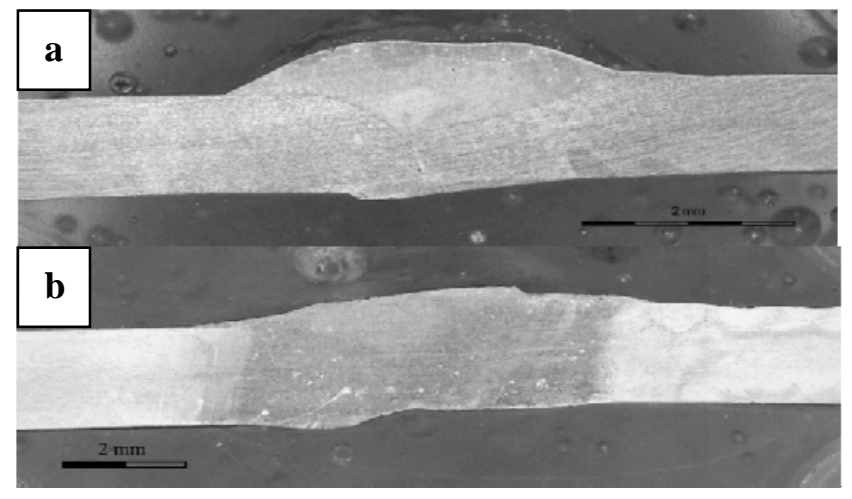

Fig.3 Cross sectional view of the welded region using a) 4043 filler and b) 4047 filler material 
defects. Fig.3 shows the cross sectional view of the welded samples. Both sample show complete fusion between the base.metals and the filler metals.

Under higher magnification, minor defects such as pores can be seen scattered throughout the welded region (Fig.4). These pores are possibly caused by dirt or gas entrapment such as hydrogen during the welding process [4], [12].

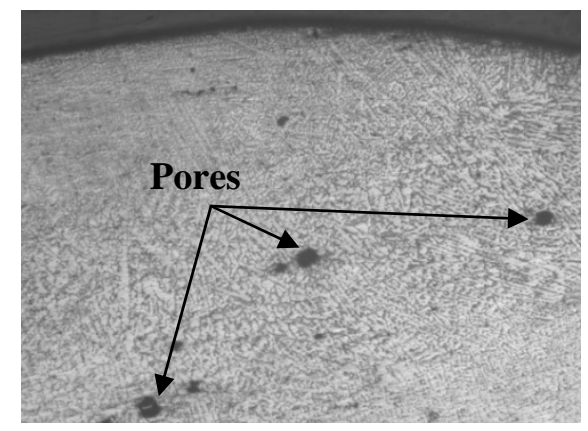

Fig.4 Pores formation in the weld metal

The common microstructures of weld metal (WM), partially melted zone (PMZ), heat affected zone (HAZ) and base metal (BM) of the welded AA6061 alloy is shown in Fig.5. Interdendritic segregation of intermetallic phases can be seen in the weld metal as well as partially melted zone. Large intermetallic particles are visible in the base metal and intergranular segregation is not prominent in that region.

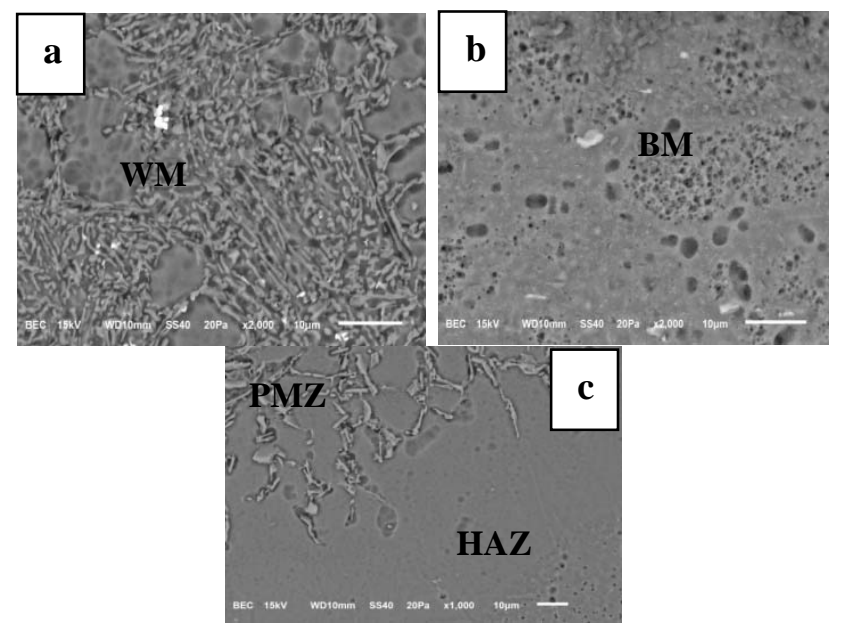

Fig.5 Microstructure of AA6061 alloy with 4047 filler in as-welded condition (×1000): (a) WM, (b) BM, (c) PMZ and HAZ

\section{B. Hardness analysis}

Fig.6 shows the Vickers hardness data of the AA6061 weldment using ER4043 (left image) and ER4047 (right image) filler metals. The Vickers hardness values are measured from the weld joint centre $(0 \mathrm{~mm})$ and are measured progressively in the horizontal $\mathrm{x}$-axis for both of the samples up to $3.5 \mathrm{~mm}$ in length from the joint centre. For ease of comparison, the hardness value at the weld centre for both samples was standardized with the same value. The BM, HAZ and WM positions are distinguished accordingly.

Both results indicate a slight decrease for 4043 specimen and an obvious decrease for 4047 specimen's hardness at the WM and HAZ. Particularly the HAZ show a lower strength value compared to $\mathrm{WM}$ for both specimens. This is attributed to the recrystallization in the HAZ. The loss is caused by the dissolution and coarsening of the precipitates. Another factor is the potential loss of alloying elements from the weld pool that may result in the reduction of strength. Elements with low boiling points such as magnesium may be lost or oxidized during the welding process [4], [11].

Fig.7 shows the normalized hardness value for both samples, where the values are normalized according to their respective BM's hardness since the region is not affected by the welding heat input. The WM and HAZ region of 4047 specimen show a significant drop of hardness value compared to its 4043 counterpart, where the WM and HAZ values relatively did not differ much with the BM.

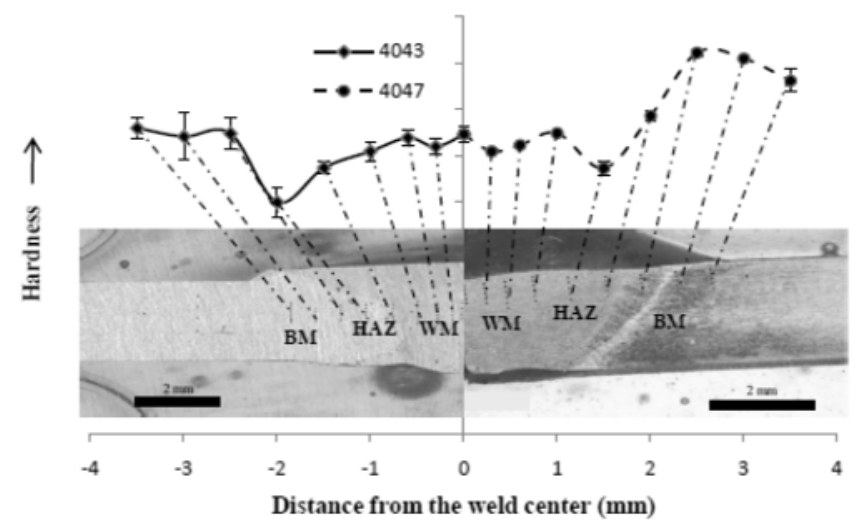

Fig.6 Comparison of Vickers hardness for different fillers

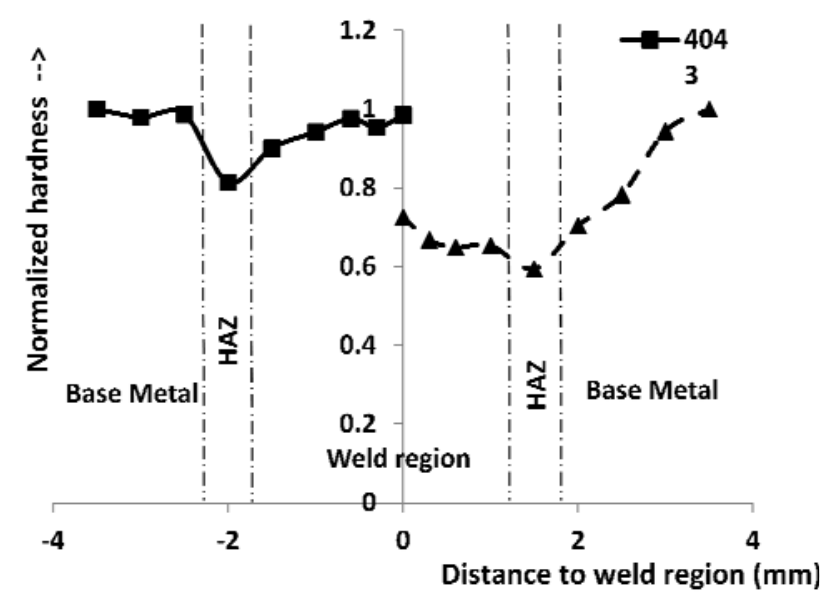

Fig.7 Normalized hardness values for 4043 and 4047.

\section{Corrosion behavior}

The potentiodynamic polarization curve was plotted and the corrosion rate was measured using the Tafel plot. Fig.8 shows the result of the corrosion rate in millimeters per year (mmPY), calculated using the IVMAN software for both 4043 
and 4047 filler metal samples. Both samples show a relatively very low corrosion rate compared to other non-ferrous metals.

However, the commonly used 4043 filler sample show a lower corrosion rate, ranging between 0.004414 to 0.007942 $\mathrm{mmPY}$, the compared to its counterpart (between 0.01035 to $0.01977 \mathrm{mmPY}$ ) indicating a much superior corrosion resistance. However, a direct correlation connecting the effect of welding current and frequency to the corrosion rate could not be achieved from the graph.

It was reported in several papers that the addition of Si-rich fillers results in an increase of Si concentration in the eutectic region of the weld fusion zone grain boundaries [1], [8]. A high Si content in the weld region promotes better corrosion resistance of the weldment [2]. However, from the results obtained, the higher percentage of silicon inside the 4047 filler did not improve the weld joint's corrosion resistance. A possible reason for this is that the Si-induced alloying element that decelerates the corrosion rate becomes super saturated rendering it to become ineffective [13].

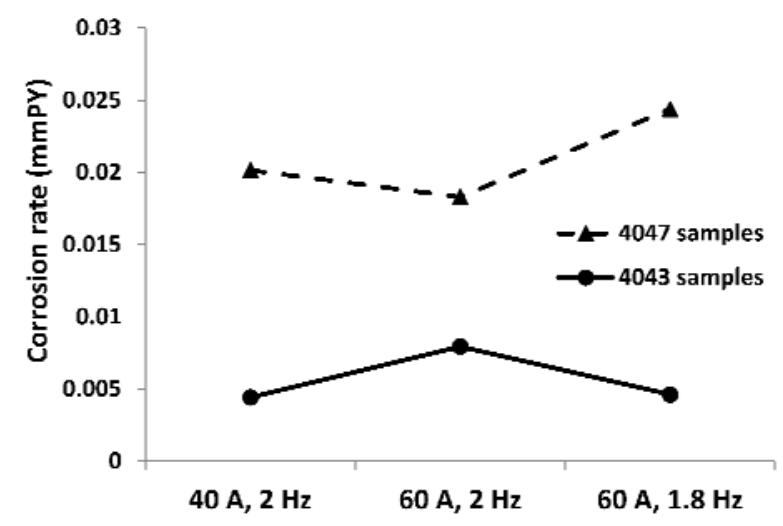

Fig.8 The corrosion rate of filler metals

\section{CONCLUSION}

The effect of corrosion on the strength and microstructure of AA6061 alloy welded by TIG welding using various aluminium-based filler materials have been investigated. The results obtained from this study can be summarized as follows:

1. The microstructure of the weld samples was observed. Interdendritic segregation of intermetallic phases can be seen in the weld metal as well as partially melted zone. Large intermetallic particles are visible in the base metal and intergranular segregation is not prominent in that region.

2. Vickers hardness of ER4043 and ER4047 filler samples both show a 'weak' region in the heat affected zone. This is attributed to the recrystallization in the HAZ. The ER4043 sample shows better hardness in the HAZ and WM compared to the ER4047 sample.

3. Corrosion analysis show that the ER4043 filler samples obtained a lower corrosion rate compared to the ER4047 filler samples.
Thus it can be concluded that ER4043 filler metals are more suitable in joining AA6061 samples due to its superior mechanical and corrosion characteristics compared to samples welded with ER4047 filler.

\section{REFERENCES}

[1] A.B.M. Mujibur Rahman, Sunil Kumar, Andrea R. Gerson, "The role of silicon in the corrosion of AA6061 aluminium alloy laser weldments," Corrosion Science, vol. 52, pp. 1969-1975, 2010.

[2] N R Mandal, "Aluminium welding”, $2^{\text {nd }}$ ed., Kharagpur: Narosa Publishing House, pp. 15, 2005.

[3] D. L. Olson, T. A. Siewert, S. Liu, G. R. Edwards, "Welding, brazing and soldering," USA: ASM International, 2007.

[4] G. Mathers, "The welding of aluminium and its alloys," Florida: Woodhead Publishing Limited, pp. 45, 2002.

[5] M. Katoh, H.W. Kerr, "Investigation of heat-affected zone cracking of GTA welds of Al-Mg-Si alloys using the Varestraint test," Welding Journal, vol. 66, pp. 360-368, 1987.

[6] K. P. Rao, N. Ramanaiah, N. Viswanathan, "Partially melted zone cracking in AA6061 welds," Materials and Design, vol. 29, pp.179-186, 2008.

[7] J. L. Song, S. B. Lin, C. L. Yang, C. L. Fan, "Effects of Si addition on intermetallic compound layer of aluminium-steel TIG welding-brazing joint," Journal of Alloys and Compounds, vol. 488, pp. 217-222, 2009.

[8] Z. Nikseresht, F. Karimzadeh, M. A. Golozar, M. Heidarbeigy, "Effect of heat treatment on microstructure and corrosion behaviour of Al6061 alloy weldment,” Materials and Design, vol.31, pp. 2643-2648, 2010.

[9] J. L. Song, S. B. Lin, C. L. Yang, G. C. Ma, H. Liu, "Spreading behaviour and microstructure characteristics of dissimilar metals TIG welding-brazing of aluminium alloy to stainless steel," Materials Science and Engineering: A, vol. 509, pp. 31-40, 2009.

[10] A.B.M. Mujibur Rahman, S. Kumar, A. R. Gerson, "Galvanic corrosion of laser weldments of AA6061 aluminium alloy," Corrosion Science, vol. 49, pp. 4339-4351, 2007.

[11] H. Bang, H. Bang, G. H. Jeon, I. H. Oh, C. S. Ro, "Gas tungsten arc welding assisted hybrid friction stir welding of dissimilar materials Al6061T6 aluminum alloy and STS304 stainless steel," Materials and Design, vol. 37, 2012, pp. 48-55.

[12] S Kou, "Welding metallurgy," $2^{\text {nd }}$ ed, New Jersey: John Wiley \& Sons Inc., pp. 66, 2005.

[13] J L Song, S B Lin, C L Yang, G H Ma, H Liu, "Spreading behavior and microstructure characteristics of dissimilar metals TIG welding-brazing of aluminum alloy to stainless steel,” Materials Science And Engineering, vol.509, pp. 31-40, 2009. 


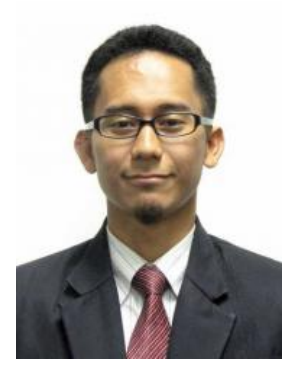

L. H. Shah was born in Kuala Lumpur, Malaysia. He graduated from Tohoku University, Sendai, Japan with a degree in master of engineering in March 2010 shortly after his bachelor's degree in mechanical engineering in 2004 at the same university.

Currently, he is a Lecturer-cum-Researcher at the Faculty of Mechanical Engineering in Universiti Malaysia Pahang, Pahang, Malaysia. He has currently shown interest in research on radiation effects on metallic glass as well as in tailor welded blanks (TWB) research area.

Mr Shah is a graduate member of the Board of Engineering Malaysia (BEM) since 2010. 